\title{
BMJ Open Broader impacts of an intervention to transform school environments on student behaviour and school functioning: post hoc analyses from the INCLUSIVE cluster randomised controlled trial
}

Christopher Bonell (D) , ${ }^{1}$ Matthew Dodd, ${ }^{1}$ Elizabeth Allen, ${ }^{2}$ Leonardo Bevilacqua, ${ }^{3}$ Jennifer McGowan, ${ }^{3}$ Charles Opondo, ${ }^{2,4}$ Joanna Sturgess, ${ }^{2,5}$ Diana Elbourne, ${ }^{2,6}$ Emily Warren, ${ }^{2,7}$ Russell M Viner (1) ${ }^{8,9}$

To cite: Bonell C, Dodd M, Allen $\mathrm{E}$, et al. Broader impacts of an intervention to transform school environments on student behaviour and school functioning: post hoc analyses from the INCLUSIVE cluster randomised controlled trial. BMJ Open 2020;10:e031589. doi:10.1136/ bmjopen-2019-031589

- Prepublication history for this paper is available online. To view these files, please visit the journal online (http://dx.doi. org/10.1136/bmjopen-2019031589).

Received 10 May 2019 Revised 05 March 2020 Accepted 08 April 2020

Check for updates

(C) Author(s) (or their employer(s)) 2020. Re-use permitted under CC BY. Published by BMJ.

For numbered affiliations see end of article.

Correspondence to Dr Christopher Bonell; chris.bonell@|shtm.ac.uk

\section{ABSTRACT}

Background We have previously reported benefits for reduced bullying, smoking, alcohol and other drug use and mental health from a trial of 'Learning Together', an intervention that aimed to modify school environments and implement restorative practice and a social and emotional skill curriculum.

Objectives To conduct post hoc theory-driven analyses of broader impacts.

Design Cluster randomised trial.

Settings 40 state secondary schools in southern England.

Participants Students aged 11/12 years at baseline. Outcomes Student self-reported measures at 24 and 36 months of: cyberbullying victimisation and perpetration; observations of other students perpetrating aggressive behaviours at school; own perpetration of aggressive behaviours in and outside school; perceived lack of safety at school; participation in school disciplinary procedures; truancy and e-cigarette use.

Results We found evidence of multiple impacts on other health (reduced e-cigarette use, cyberbullying perpetration, perpetration of aggressive behaviours) and educational (reduced participation in school disciplinary procedures and truancy) outcomes.

Conclusion These analyses suggested that the intervention was effective in bringing about a broader range of beneficial outcomes, adding to the evidence that the intervention is a promising approach to promote adolescent health via an intervention that is attractive to schools.

Trial registration number ISRCTN10751359.

\section{INTRODUCTION}

We have previously reported the results of our main trial analyses from the INCLUSIVE cluster randomised controlled trial (RCT) of a multicomponent intervention aiming to transform school environments to render these healthier places, reporting effectiveness
Strengths and limitations of this study

- This study was a rigorously conducted experimental evaluation.

- These are additional analyses that were not included in our original protocol, so caution is required in the interpretation of significant findings.

- However, the analyses are guided by explicit, theorydriven hypotheses, as set out in our introduction, rather than being the product of subjecting all measures to analysis and merely reporting significant findings.

- We relied on student self-reports as these were less likely than school routine data to be biased by delivery of the intervention.

- While our measure of student participation in disciplinary procedures had high inter-item reliability, this was lower for our measure of student perpetration of aggressive behaviours in or outside school, so our conclusions regarding effects on this outcome should be cautious.

across multiple health domains. ${ }^{1}$ In this paper, we aimed to explore the extent to which the intervention 'disrupted' the school 'system' to achieve more impacts.

There is increasing interest in the implications of 'systems' thinking for evaluating health interventions. ${ }^{2}$ Interventions can be viewed as 'interruptions' to complex systems, the consequences of which may go beyond the primary and secondary health outcomes assessed by trials. This perspective is of particular relevance for our intervention since this aimed to promote students' health not by improving individual students' knowledge, skills or attitudes, but rather by modifying the overall 
school environment so that it is more engaging and thus an easier environment to choose healthy rather than risky behaviours. Due to our interventions' focus on settings and use of multiple components, it is particularly likely that its impact might have gone beyond our prehypothesised primary and secondary outcomes to impact on the school systems' broader functioning. ${ }^{3}$ This paper therefore draws on theory to develop and test hypotheses about what the broader impacts of our intervention might have been.

Our intervention aimed to transform the school environment to make this more salutogenic, informed by previous evidence of effective interventions. ${ }^{4-6}$ It aimed to do so by: (a) using 'restorative approaches' to address conflict; (b) rendering schools more participative by involving students and staff in an action group to review local data on student experiences and use this to change school policies related to behaviour management, and lead the intervention and (c) providing a social and emotional skills curriculum for students aged $12-15$ years. ${ }^{17}$ Restorative approaches aim to enable victims to communicate to perpetrators the harms experienced, and enable perpetrators to recognise and take steps to remedy this and avoid further harms. ${ }^{8}$ Restorative approaches include primary prevention of conflict (via 'circle-time', which brings students together to build and maintain relationships) and/or secondary prevention to resolve incidents (such as 'conferencing' to address serious incidents).

The intervention was supported by a theory of change that was informed by an appropriate settings-based social theory: the theory of human functioning and school organisation. ${ }^{9}$ We theorised that schools can reduce bullying and aggression by transforming the school environment to build student commitment to learning and sense of belonging in school. It was theorised that this in turn can be achieved by improving relationships between and among staff and students (via the action group and restorative practice) and by better integrating students' academic education and broader personal development (via the curriculum and restorative practice). It was further theorised that by increasing student commitment to and belonging in school, this would reduce student interest and involvement in antisocial peer groups and behaviours.

Our main trial paper examined intervention effects on the primary and secondary outcomes described in the trial protocol. We reported a range of significant intervention effects in terms of reduced bullying victimisation (co-primary outcome) and use of tobacco, alcohol and other drugs, reduced contact with police, as well as improved mental well-being, psychological functioning and healthrelated quality of life among adolescent students (secondary outcomes) at 36 months (table 1). ${ }^{1}$ We found no significant effect for perpetration of aggression in school (co-primary outcome) or for age of sexual debut, use of contraception at first sex, bullying perpetration or use of National Health Service (secondary outcomes). The intervention was implemented with variable fidelity, with this being lower in year 3. Training, action groups and restorative practices but not the curriculum were delivered with good fidelity. ${ }^{1}$
Table 1 Outcomes assessed in the main trial paper and the post hoc analysis

\begin{tabular}{|c|c|c|}
\hline $\begin{array}{l}\text { Outcomes assessed in } \\
\text { main trial paper }\end{array}$ & $\begin{array}{l}\text { Evidence of } \\
\text { significant } \\
\text { beneficial effect on } \\
\text { this outcome }\end{array}$ & $\begin{array}{l}\text { Outcomes } \\
\text { assessed in } \\
\text { this post hoc } \\
\text { analysis }\end{array}$ \\
\hline Bullying victimisation & $\sqrt{ }$ & $\begin{array}{l}\text { Cyberbullying } \\
\text { victimisation }\end{array}$ \\
\hline $\begin{array}{l}\text { Aggression perpetration } \\
\text { in school }\end{array}$ & & $\begin{array}{l}\text { Cyberbullying } \\
\text { perpetration }\end{array}$ \\
\hline $\begin{array}{l}\text { Health-related quality } \\
\text { of life }\end{array}$ & $\sqrt{ }$ & $\begin{array}{l}\text { Observing } \\
\text { other students' } \\
\text { perpetrating } \\
\text { aggression in } \\
\text { school }\end{array}$ \\
\hline Mental well-being & $\sqrt{ }$ & $\begin{array}{l}\text { Aggression } \\
\text { perpetration } \\
\text { either in or out of } \\
\text { school }\end{array}$ \\
\hline Psychological problems & $\sqrt{ }$ & $\begin{array}{l}\text { Perceived lack of } \\
\text { safety at school }\end{array}$ \\
\hline Bullying perpetration & & $\begin{array}{l}\text { Participation in } \\
\text { school discipline } \\
\text { procedures }\end{array}$ \\
\hline Cigarette smoking & $\sqrt{ }$ & Truancy \\
\hline Alcohol use & $\sqrt{ }$ & E-cigarette use \\
\hline Drunkenness & $\sqrt{ }$ & \\
\hline Illicit drug use & $\sqrt{ }$ & \\
\hline \multicolumn{3}{|l|}{ Age of sexual debut } \\
\hline \multicolumn{3}{|l|}{$\begin{array}{l}\text { Contraception at first } \\
\text { sex }\end{array}$} \\
\hline \multicolumn{3}{|l|}{ NHS service use } \\
\hline Police contact & $\sqrt{ }$ & \\
\hline
\end{tabular}

NHS, National Health Service.

The first area where we anticipated beneficial broader impacts is cyberbullying. Our main trial analyses reported effects of the intervention on our primary outcome of reduced bullying victimisation (Gatehouse Bullying Scale).$^{10}$ This is an important result given the prevalence of bullying ${ }^{11}$ and its association with concurrent and future physical and mental health harms. ${ }^{12-18}$ However, this analysis was insensitive to any effects of the intervention on cyberbullying. Cyberbullying is an increasingly prevalent aspect of bullying, associated with significant harms. ${ }^{19}$ We did not include this in our list of primary or secondary outcomes because this mostly occurs outside school. However, assessing this would be appropriate given that our intervention is theorised to work by decreasing student interest in antisocial behaviour in general not limited to the school site.

Our second area of exploration is perpetration of aggression. Our main trial analyses found no evidence of effects on our other primary outcome of self-reported perpetration of school-based aggression (Edinburgh Study of Youth Transitions (ESYTC) measure). ${ }^{20}$ This was an unexpected finding 
given the reduction in bullying victimisation, and given the intervention was theorised to reduce bullying victimisation and perpetration of aggression via a common mechanism involving increased student commitment to school and reducing student involvement in antisocial peer groups and behaviours. A systematic review has previously concluded that trials of whole-school interventions addressing violence sometimes find effects on victimisation but not perpetration, possibly because participants under-report perpetration of socially unacceptable behaviours particularly in school. ${ }^{5}$ Our student questionnaire also included a measure for students to report their observations of other students perpetrating aggressive behaviours, thus perhaps providing a broader assessment of aggressive behaviours in school and less prone to under-reporting. Therefore, we hypothesised that we will find effects of the intervention on this measure of student-reported observations of other students perpetrating aggressive behaviours at school. Furthermore, our primary measure of perpetration of aggression focused only on school-based behaviours. Since our intervention aimed to reduce students' general involvement in antisocial peer groups and behaviours, rather than merely reducing such behaviours in school, we hypothesised that the intervention would be effective in reducing a broader measure of students' own perpetration of aggressive behaviours not specific to school which we included in our questionnaire.

Our third focus for this paper is on impacts of the intervention on the overall functioning of the school system. Interventions effective in reducing bullying and promoting student health are more likely to be scaled up if schools and policymakers can see evidence that such interventions also reduce school workloads and enhance education. ${ }^{21}$ Our theory of change centred on enhancing student commitment to school and reducing student involvement in antisocial behaviours, and we found effects not only for reduced bullying victimisation but also for increased student commitment to school. ${ }^{22}$ We therefore hypothesised that this will translate into students reporting: feeling safer at school, less participation in school disciplinary procedures and less truancy.

Our final focus in this paper is on e-cigarette use. As indicated earlier, we found effects for smoking but our measure focused on the smoking of tobacco rather than use of e-cigarettes. However, we would also expect the intervention to reduce the latter. There are increasing concerns about the increasing prevalence of e-cigarette use among young people with some evidence that this is associated with subsequent increase in smoking tobacco. ${ }^{23}$ We therefore hypothesised that rates of use of e-cigarettes are lower among schools in the intervention group.

In summary, we hypothesised that the intervention was effective not only with regard to the primary and secondary outcomes measured described in our protocol, but also in promoting a broader range of unintended but beneficial impacts via its disruption of the school system, reducing student-reported: cyberbullying victimisation and perpetration; observations of other students perpetrating aggressive behaviours at school; own perpetration of aggressive behaviours in and outside school; perceived lack of safety at school; participation in school disciplinary procedures; truancy and e-cigarette use (table 1). Given our previous finding that intervention effects on primary and secondary outcomes were apparent at 36-month but not 24-month follow-up, which is in line with previous evidence that the effects of whole-school interventions build over time as they take time to transform the school environment, ${ }^{6}$ we hypothesised that this would also apply to the outcomes examined in this paper.

\section{METHODS}

Full details of the intervention and trial were reported in our protocol and main trial report. ${ }^{17}$ We conducted a twoarm parallel repeat cross-sectional cluster RCT of the intervention in 40 secondary schools in south-east England. To be included, schools had government inspections rating of 'requires improvement' or above and were recruited by the trial team via emails. Our student population consisted of all students: at baseline in 2014 who were at the end of year 7 (11-12 years); who were then in year 9 at interim 24-month follow-up in 2016 and who were in year 10 at final 36-month follow-up in 2017. Some students moved schools, hence the study was repeated cross-sectional since all were included in analyses. Students were surveyed using paper questionnaires in classes under exam conditions by trained fieldworkers blinded to allocation. After baseline surveys, schools were allocated 1:1 to intervention or control by computer-generated random numbers stratified by: single-sex versus mixed-sex school; school-level student free-school-meal eligibility $(0 \%-23 \%$; $>23 \%)$ indicating poverty and General Certificate of Secondary Education results accounting for student baseline attainment (above/ below the median score of 1000 for England).

The intervention involved all staff in intervention schools receiving training to use restorative practice to prevent and address student conflicts. Approximately 5-10 key staff per school were trained in-depth to deliver restorative conferences dealing with more serious incidents. All schools received a manual to guide the convening and running of a school action group comprising at least six staff and six students, led by a member of the school's senior leadership team. An external facilitator supported action groups in the first two but not the third year of intervention, when they moved to being self-directed. Action groups reviewed anonymised findings from the school's baseline survey to understand local needs and aimed to coordinate the intervention and revise policies so that these supported the use of restorative practice. Schools were provided with materials to guide delivery of a social and emotional skills curriculum for students in years $8-10$ to receive 5-10 hours teaching per year. The curriculum addressed bullying and aggression but not specific to a particular setting such as school or online. Schools in the control group continued with usual practice.

Our measures analysed in this paper are described in table 2. Each of these were included in student 
Table 2 Outcome measures

\begin{tabular}{|c|c|c|c|c|}
\hline Outcome measure & Question & Responses & Source & Variable \\
\hline \multirow[t]{3}{*}{ Cyberbullying victimisation } & \multirow{3}{*}{$\begin{array}{l}\text { Have you been bullied } \\
\text { through mobile phone } \\
\text { use or on the internet in } \\
\text { the last } 3 \text { months? }\end{array}$} & No I haven't & \multirow{3}{*}{$\begin{array}{l}\text { Adapted from Daphne } \\
\text { measure of cyberbullying }\end{array}$} & \multirow[t]{3}{*}{ Binary any yes/no } \\
\hline & & Yes, once or twice & & \\
\hline & & Yes, about once a week & & \\
\hline \multirow[t]{4}{*}{ Cyberbullying perpetration } & \multirow{4}{*}{$\begin{array}{l}\text { Have you ever bullied } \\
\text { anyone else using your } \\
\text { mobile phone or using } \\
\text { the internet? }\end{array}$} & No I haven't & \multirow{4}{*}{$\begin{array}{l}\text { Adapted from Daphne } \\
\text { measure of cyberbullying }\end{array}$} & \multirow[t]{4}{*}{ Binary any yes/no } \\
\hline & & Yes, once or twice & & \\
\hline & & $\begin{array}{l}\text { Yes, two or three times a } \\
\text { month }\end{array}$ & & \\
\hline & & Yes, about once a week & & \\
\hline \multirow{6}{*}{$\begin{array}{l}\text { Student-reported } \\
\text { observations of other } \\
\text { students perpetrating } \\
\text { aggressive behaviours at } \\
\text { school }\end{array}$} & \multirow{6}{*}{$\begin{array}{l}\text { Which of the following } \\
\text { have you seen happen } \\
\text { at this school in the last } \\
3 \text { months of school }\end{array}$} & Girls fighting & \multirow{6}{*}{ New } & \multirow{6}{*}{$\begin{array}{l}\text { Score out of } 7 \text { (point per } \\
\text { item) }\end{array}$} \\
\hline & & $\begin{array}{l}\text { Someone threatening } \\
\text { someone }\end{array}$ & & \\
\hline & & $\begin{array}{l}\text { A student trying to hurt } \\
\text { another student }\end{array}$ & & \\
\hline & & $\begin{array}{l}\text { Someone robbing money } \\
\text { or a mobile phone }\end{array}$ & & \\
\hline & & $\begin{array}{l}\text { Someone letting off a } \\
\text { firework }\end{array}$ & & \\
\hline & & Someone carrying a knife & & \\
\hline
\end{tabular}

Perpetration of antisocial behaviour in or outside school
During the last 3 months of school

Did you ever carry a knife No

or other weapon with you for protection or in case it Adapted from ESYTC measure of antisocial behaviour
Score out of 4 (4 items with each no/yes 0-1) was needed in a fight?

Did you use force, threats Yes

or a weapon to steal money or something else from somebody?

Did you damage or destroy property that did not belong to you on purpose (eg, windows, cars or street lights)?

Did you ever set fire or try

to set fire to something on purpose (eg, bus shelter, shop, etc)? 
Table 2 Continued

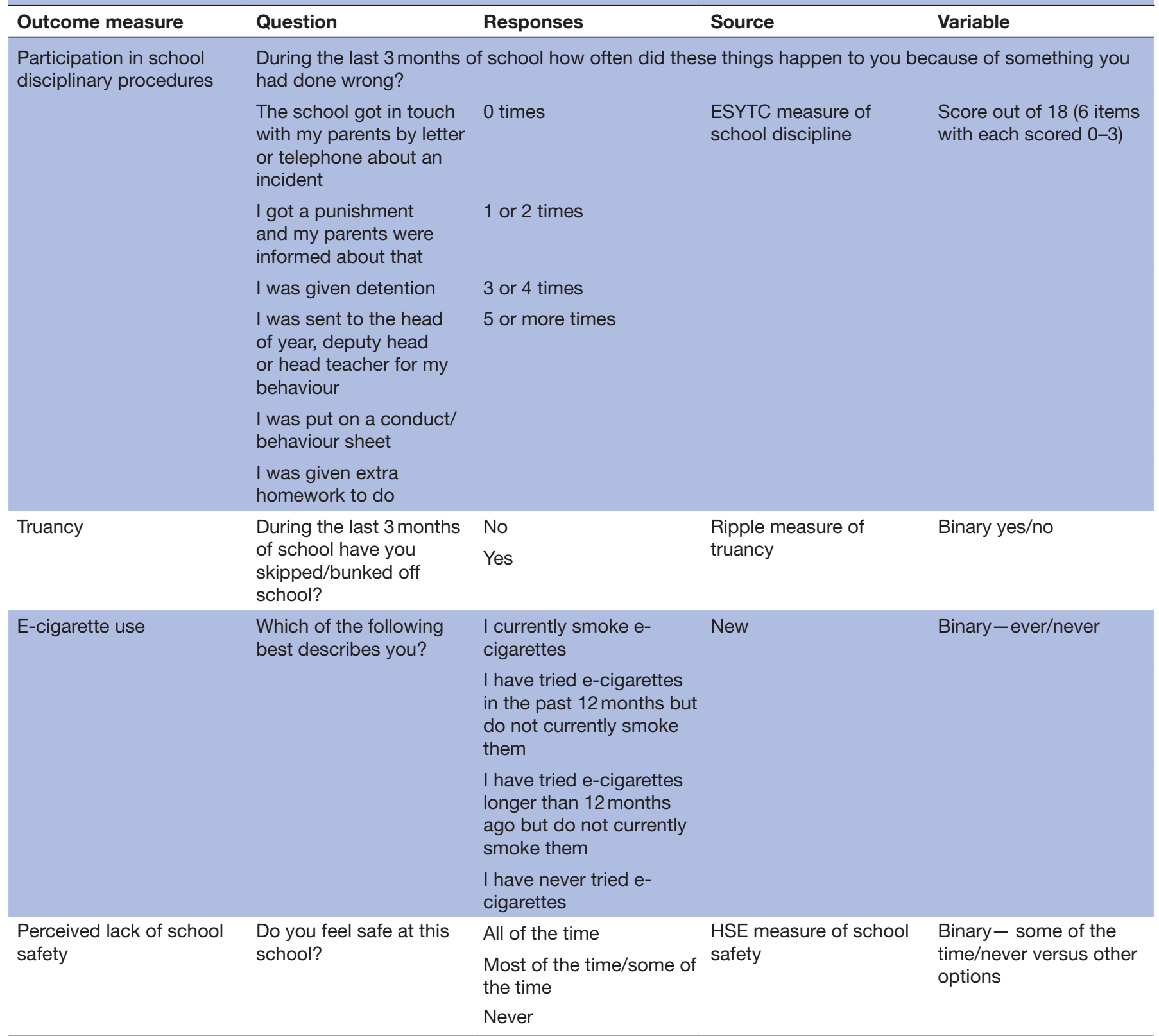

ESYTC, Edinburgh Study of Youth Transitions; HSE, Healthy School Ethos.

questionnaires used to assess trial outcomes but did not form part of our specified trial outcomes. We adapted Smith and colleagues' measure of cyberbullying perpetration and victimisation. ${ }^{24}$ We developed a new singleitem measure of student-reported observations of other students perpetrating aggressive behaviours at school, where students indicated which behaviours they had observed at school to provide a quantitative measure scored 0-7. We examined students' own perpetration of aggressive behaviours in or outside school using a modified four-item version of the ESYTC measure of antisocial behaviours. ${ }^{20}$ Students reported which behaviours they had engaged in to give a quantitative score $0-4$. We assessed perceived lack of school safety using a single item derived from the Healthy School Ethos study. ${ }^{25}$
We assessed student participation in school disciplinary procedures using the six-item ESYTC measure of school discipline. ${ }^{20}$ This assessed students' frequency of engagement (never; one or two times; three or four times and five or more times) with six disciplinary procedures to provide a quantitative score $0-18$. We assessed school truancy using a student-reported single-item measure previously used in the Ripple trial. ${ }^{26}$ We developed a new single-item measure of e-cigarette use.

\section{PATIENT AND PUBLIC INVOLVEMENT}

The trial involved young people from The National Children's Bureau Young Researchers' Group in advising on intervention and research methods during three meetings 
at the set-up phase. School action groups comprised part of the intervention and enabled students to participate in planning and coordinating intervention activities.

As with our analysis of primary and secondary outcomes, our analyses of outcomes in this paper were intention-to-treat, including all schools and participants at each wave. Each outcome measure was analysed using a separate mixed model with the measure from each time point treated as a repeated measure. Fixed effects of time (baseline, 24 months and 36 months) and the interaction between arm and time were specified, and estimated baseline measures were constrained to be identical in the two arms of the trial. This is equivalent to adjusting for baseline but enables data from all participants to contribute to the analysis, even where there are missing data at follow-up. We specified random effects for school and participants, to allow for correlations within schools and repeated measures within participants. We undertook analyses adjusted for baseline measures of outcomes, sex, ethnicity, socioeconomic status (Family Affluence Scale (FAS) ) as well as for the school-stratifying factors.

We used appropriate multilevel models to examine the effects of the intervention. For quantitative measures, we used mixed linear-regression models with random effects at the level of participants and schools to estimate adjusted mean differences (MD) between arms. For binary outcomes, we used mixed-effects logistic regression models, with random effects for schools and individuals, reporting unadjusted and adjusted OR. Evidence for any moderation of intervention effects on our outcomes by student sex and socioeconomic status (FAS) was assessed by Wald tests for the treatment by subgroup interaction terms. We also calculated Cronbach's alpha to assess the inter-item reliability of our multiquestion measures of student perpetration of aggressive behaviours in or outside school and student participation in school disciplinary procedures.

Informed consent was sought from head teachers for randomisation and intervention, and from students, deemed competent by schools to do so, for participation in surveys. Parents were informed about the study and could withdraw their children from research activities.

\section{RESULTS}

In total, 6667 students in 40 schools provided data at baseline, representing a participation rate of $93.6 \%$ of registered students $(92.9 \%$ in intervention arm; $94.3 \%$ control arm). Student characteristics and baseline reports of the outcomes examined in this paper are reported in table 3, with good balance between arms.

All schools participated in the surveys at 24 and 36 months, with student participation rates being similar by arms (figure 1).

Cronbach's alpha for our ESYTC measures of student perpetration of aggressive behaviours in or outside school was 0.55 and for our ESYTC measure of student participation in school disciplinary procedures was 0.79 .
Our broader student outcomes at 24 and 36 months are reported in table 4 . At 24 months comparing intervention with control schools, we found lower rates of: cyberbullying victimisation $(\mathrm{OR}=0.77 ; 95 \% \mathrm{CI} 0.61,0.98 ; \mathrm{p}=0.035)$ but not perpetration and e-cigarette use $(\mathrm{OR}=0.6095 \% \mathrm{CI}$ $0.43,0.83 ; \mathrm{p}=0.002)$. Students in intervention schools were more likely to report lack of perceived school safety at 24 months than controls (OR=1.38, 95\% CI 1.10, 1.75; $\mathrm{p}=0.006$ ). There was no evidence of difference between arms in: student-reported observations of other students perpetrating aggressive behaviours at school; perpetration of aggressive behaviours in or outside school or truancy. There was weak to moderate evidence of lower reported participation in school disciplinary procedures in intervention compared with control schools at 24 months (MD=-0.16, 95\% CI $-0.32,0.00 ; \mathrm{p}=0.043)$.

At 36 months comparing intervention and control schools, we found reduced rates of: cyberbullying perpetration $(\mathrm{OR}=0.65,95 \%$ CI $0.48,0.88 ; \mathrm{p}=0.005)$ but not victimisation; perpetration of aggression in or outside school $(\mathrm{MD}=-0.031,95 \% \mathrm{CI}-0.056$ to $0.006 ; \mathrm{p}=0.016)$; participation in school disciplinary procedures $(\mathrm{MD}=-0.320$, $95 \% \mathrm{CI}-0.480$ to $0.150 ; \mathrm{p}<0.001)$; truancy $(\mathrm{OR}=0.64$, $95 \%$ CI $0.49,0.84 ; \mathrm{p}=0.001)$ and e-cigarette use $(\mathrm{OR}=0.59$, $95 \%$ CI $0.42,0.82 ; \mathrm{p}=0.002)$. There was weak to moderate evidence of lower student-reported observations of other students perpetrating aggressive behaviours at school $(\mathrm{MD}=0.10,95 \%$ CI $0.00,0.20 ; \mathrm{p}=0.049)$. There were no evidence of difference in perceived school safety.

Table 5 presents outcomes and follow-up points for which there was evidence of moderation. We found evidence that intervention effects on cyberbullying perpetration at 24 months were moderated by student sex, such that effects were larger for boys $(\mathrm{p}=0.002)$. Intervention effects on observed aggression by other students at 24 months were moderated by student sex and socioeconomic status, with effects larger for girls $(p=0.02)$ and affluent students $(\mathrm{p}=0.03)$. Effects on perceived lack of school safety at 24 months were larger for girls $(\mathrm{p}=0.001)$, and at 36 months were larger for students from poorer families $(\mathrm{p}=0.002)$. Effects on participation in school disciplinary procedures at 24 and 36 months were larger for boys $(\mathrm{p}<0.001$ and 0.001 , respectively). Effects on truancy at 24 months were larger for boys $(p=0.015)$. Effects on e-cigarette use at 24 and 36 months were larger for boys $(\mathrm{p}=0.014$ and $<0.001$ respectively $)$.

\section{DISCUSSION}

\section{Summary of key findings}

We reported an analysis of broader system impacts on student health and school functioning outcomes of this settings-based intervention aim to render schools more health-promoting environments which was previously reported to be effective in reducing bullying victimisation and use of alcohol, tobacco and drugs, as well as promoting mental and physical health. ${ }^{1}$ We found evidence at 36 months but not 24 months of intervention 
Table 3 Characteristics of schools and students at baseline by trial arm

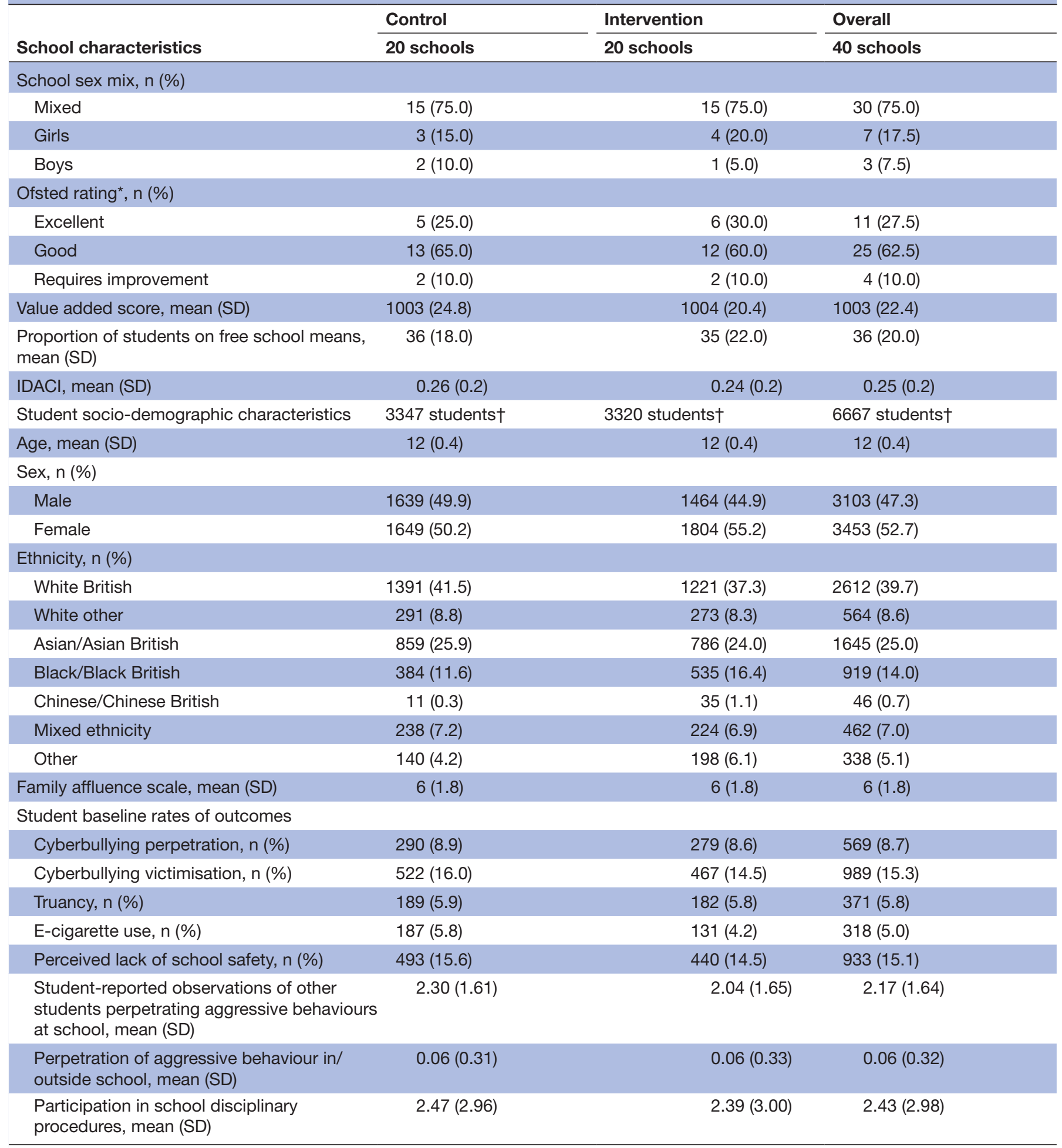

${ }^{*}$ One control school did not have an Ofsted rating.

†The number of students who responded at this survey; actual number of responses to each question varies, but item non-response is similar across arms.

ADACI, Income Deprivation Affecting Children Index.

effects on: cyberbullying perpetration; student observations of aggression by other students; students' own perpetration of aggressive behaviours in or outside school; truancy and participation in school disciplinary procedures. There was evidence of an effect on increased student perceptions of lack of school safety at 24 months but not 36 months. There was also evidence of an effect at 24 months but not 36 months on cyberbullying victimisation. We found evidence of an effect on e-cigarette use at both time points. 


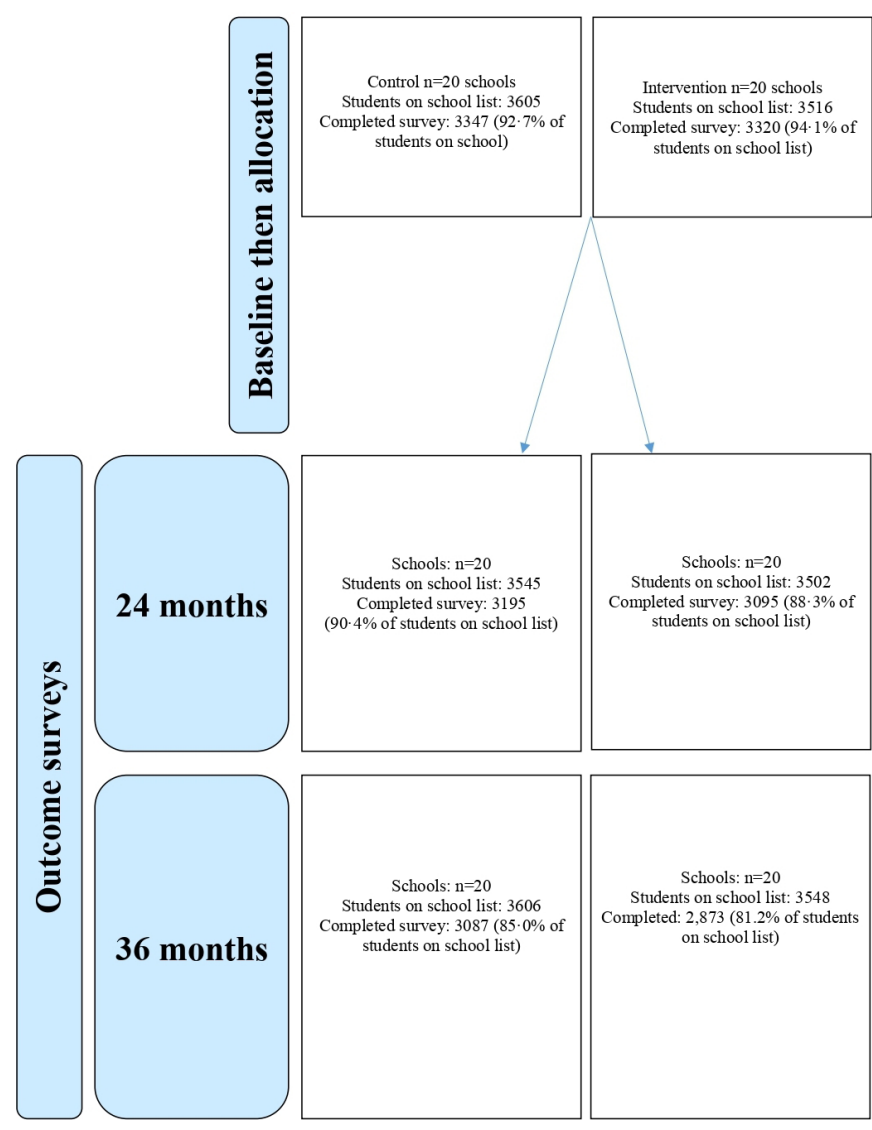

Figure 1 Trial participants.

These findings suggest that our intervention, which aimed to reduce bullying via making schools more engaging environments, and which did not explicitly focus on cyberbullying, might nonetheless have been effective in reducing this. Our findings also suggest that the intervention might, contrary to the main analyses, have reduced rates of aggression including aggression beyond the school environment. However, results across time points and measures are somewhat inconsistent, probably as a result of chance. Our intervention also appears to have reduced student use of e-cigarettes, which is an important finding given increasing concerns about this as a gateway to tobacco use. ${ }^{23}$ This evidence of additional health impacts provides further evidence in support of the intervention theory of change that it is possible to improve young people's health across a range of areas by addressing the school as a potentially salutogenic environment rather than merely as a setting for individual-focused health education in classrooms. Furthermore, our finding of broader impacts on school functioning in terms of reduced truancy and student involvement in discipline systems provides evidence of the knock-on consequences of a health intervention disrupting the school system to achieve impacts on the domain of education.

Intervention effects were moderated in some cases by student sex and family affluence. Effects were larger for boys regarding reduced cyberbullying perpetration and truancy at 24 months, and reduced participation in school disciplinary procedures and e-cigarette use at 24 and 36 months. For girls, intervention effects were greater regarding reduced observed aggression by other students and decreased perceived school safety at 24 months. Effects for decreased perceived school safety at 36 months were also larger for students from poorer families. Effects on reduced observed aggression at 24 months were larger for affluent students. These findings contrast with moderator analyses for our primary and secondary outcomes, where benefits were generally larger for boys and no different for those from poorer families. ${ }^{1}$

Our finding of increased student perceptions of lack of safety in intervention versus control schools at 24 months, and among poorer students at 36 months, is of concern. We noted that this association runs counter to our previous findings for actual rates of bullying victimisation $^{1}$ and to the findings in this paper on aggression. This finding may be due to chance. However, it might be explained by the intervention's focus on bullying and aggression sensitising students to issues of safety, leading them to feel unsafe at the initial (24 month) follow-up but dissipating as the intervention became normalised and exerted positive effects on bullying and aggression.

These moderator analyses add to the evidence from our main analyses that the intervention might generally have been more effective for boys than girls. As with our main trial analyses, there was less evidence for moderation by socioeconomic status. These findings of gender inequity of effects is in line with some previous research suggesting that whole-school interventions, including those to reduce violence, can sometimes be more effective for boys than girls. ${ }^{14}$ This might be because, in such interventions, violence and other problem behaviours among boys receive more attention than those experienced by girls.

\section{Strengths and limitations}

This study was a rigorously conducted experimental evaluation. These are additional analyses not included in our original protocol. Therefore, caution is required in the interpretation of significant findings. However, the analyses are guided by explicit, theory-driven hypotheses, as set out in our introduction, rather than being the product of subjecting all measures to analysis and merely reporting significant findings. We relied on student self-reports as these were less likely than school routine data to be biased by delivery of the intervention. Where possible, we used reliable existing measures. While our measure of student participation in disciplinary procedures had high inter-item reliability, this was lower for our measure of student perpetration of aggressive behaviours in or outside school so our conclusions regarding effects on this outcome should be cautious.

\section{Implications for policy and research}

Our findings suggest that the intervention disrupted school systems to achieve a range of unintended but beneficial 


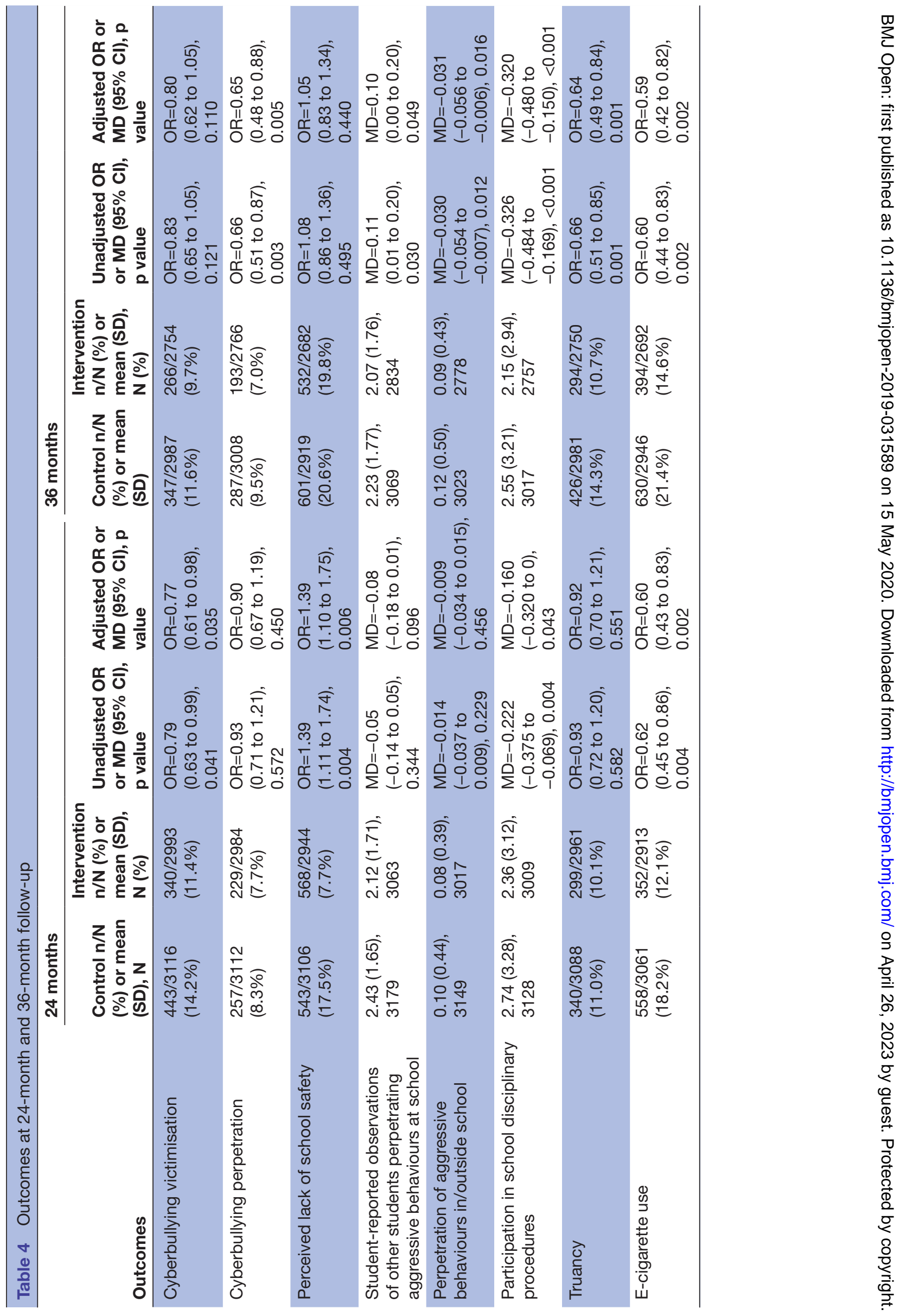


Table 5 Moderation

\begin{tabular}{|c|c|c|c|c|c|}
\hline \multirow[b]{2}{*}{ Outcome } & \multirow{2}{*}{$\begin{array}{l}\text { Follow-up } \\
\text { (months) where } \\
\text { evidence of } \\
\text { moderation }\end{array}$} & \multicolumn{2}{|l|}{ Moderator } & \multirow[b]{2}{*}{ Association (95\% Cl) } & \multirow[b]{2}{*}{$\begin{array}{l}\text { Interaction } \\
\text { ( } p \text { value) }\end{array}$} \\
\hline & & Variable & Categories & & \\
\hline \multirow{2}{*}{$\begin{array}{l}\text { Perpetration } \\
\text { cyberbullying }\end{array}$} & \multirow[t]{2}{*}{24} & \multirow[t]{2}{*}{ Sex } & Boys & $\mathrm{OR}=0.61(0.41$ to 0.89$)$ & \multirow[t]{2}{*}{0.002} \\
\hline & & & Girls & 1.19 (0.85 to 1.67$)$ & \\
\hline \multirow[t]{5}{*}{ Observed aggression } & \multirow[t]{5}{*}{24} & \multirow[t]{2}{*}{ Sex } & Boys & $\mathrm{MD}=0.01(-0.11$ to 0.13$)$ & \multirow[t]{2}{*}{0.02} \\
\hline & & & Girls & $M D=-0.15(-0.26$ to -0.04$)$ & \\
\hline & & \multirow[t]{3}{*}{ Family affluence } & Low & $\mathrm{MD}=-0.18(-0.62$ to 0.25$)$ & \multirow[t]{3}{*}{0.03} \\
\hline & & & Middle & $\mathrm{MD}=0.04(-0.09$ to 0.18$)$ & \\
\hline & & & High & $\mathrm{MD}=-0.14(-0.25$ to --0.03$)$ & \\
\hline \multirow[t]{5}{*}{ Lack of safety } & \multirow[t]{2}{*}{24} & \multirow[t]{2}{*}{ Sex } & Boys & $\mathrm{OR}=0.99(0.73$ to 1.35$)$ & \multirow[t]{2}{*}{0.001} \\
\hline & & & Girls & $\mathrm{OR}=1.74(1.33$ to 2.27$)$ & \\
\hline & \multirow[t]{3}{*}{36} & \multirow[t]{3}{*}{ Family affluence } & Low & $\mathrm{OR}=3.07(0.99$ to 9.54$)$ & \multirow[t]{3}{*}{0.002} \\
\hline & & & Middle & $\mathrm{OR}=0.72(0.51$ to 1.01$)$ & \\
\hline & & & High & $\mathrm{OR}=1.23(0.94$ to 1.60$)$ & \\
\hline \multirow{4}{*}{$\begin{array}{l}\text { Participation in } \\
\text { school disciplinary } \\
\text { procedures }\end{array}$} & \multirow[t]{2}{*}{24} & \multirow[t]{2}{*}{ Sex } & Boys & $\mathrm{MD}=-0.39(-0.60$ to -0.19$)$ & \multirow[t]{2}{*}{$<0.001$} \\
\hline & & & Girls & $\mathrm{MD}=0.02(-0.17$ to 0.20$)$ & \\
\hline & \multirow[t]{2}{*}{36} & \multirow[t]{2}{*}{ Sex } & Boys & $\mathrm{MD}=-0.55(-0.76$ to -0.34$)$ & \multirow[t]{2}{*}{0.001} \\
\hline & & & Girls & $\mathrm{MD}=-0.14(-0.33$ to 0.05$)$ & \\
\hline \multirow[t]{2}{*}{ Truancy } & \multirow[t]{2}{*}{24} & \multirow[t]{2}{*}{ Sex } & Boys & $\mathrm{OR}=0.69(0.48$ to 0.99$)$ & \multirow[t]{2}{*}{0.015} \\
\hline & & & Girls & $\mathrm{OR}=1.13(0.83$ to 1.55$)$ & \\
\hline \multirow[t]{4}{*}{ E-cigarette use } & 24 & Sex & Boys & $\mathrm{OR}=0.45(0.30$ to 0.67$)$ & 0.014 \\
\hline & & & Girls & $\mathrm{OR}=0.80(0.54$ to 1.20 & \\
\hline & 36 & & Boys & $\mathrm{OR}=0.35$ (0.23 to 0.53 & $<0.001$ \\
\hline & & & Girls & $\mathrm{OR}=0.94$ (0.63 to 1.40$)$ & \\
\hline
\end{tabular}

impacts on student health and school functioning not captured in the main trial analyses. ${ }^{23}$ These results suggest that it is possible to achieve public health improvements across a range of outcomes using a single coordinated intervention which focuses on environmental transformation rather than individual behaviour change. This is important given the impracticality of implementing different interventions for multiple outcomes in schools. ${ }^{21}$ Our findings also suggest important benefits for education and school functioning. It appears that the intervention's previously reported effects on reducing bullying victimisation and improving student commitment to school ${ }^{122}$ translated into reduced student truancy and participation in school disciplinary procedures. This is especially an important evidence for school leaders suggesting the potential educational benefits of whole-school health interventions. Our analyses suggest this intervention worked more effectively for boys than girls. Further research is needed on how to ensure school-based interventions are more equitable, perhaps by ensuring these address less overt forms of student disengagement and conflict.

\section{Author affiliations}

${ }^{1}$ Public Health and Policy, London School of Hygiene and Tropical Medicine, London, UK
${ }^{2}$ Department of Medical Statistics, London School of Hygiene \& Tropical Medicine, London, UK

${ }^{3}$ University College London, London, UK

${ }^{4}$ London School of Hygiene and Tropical Medicine, London, UK

${ }^{5}$ Department of Population Health, London School of Hygiene and Tropical Medicine, London, UK

${ }^{6}$ EPH, LSHTM, London, UK

${ }^{7}$ Faculty of Epidemiology and Population Health, London School of Hygiene \& Tropical Medicine, London, UK

${ }^{8}$ Population, Policy and Practice Research Programme, UCL Institute of Child Health, London, UK

${ }^{9}$ Institute of Child Health, University College London, Londn, UK

Acknowledgements We are grateful to the staff and students of participating schools for their dedication to the intervention and completion of the outcome surveys and process evaluation surveys and interviews. We are very grateful for the advice and support of our Trial Steering Committee and Data Monitoring Committee. All those who contributed significantly to this work are listed in these acknowledgements.

Contributors All those who contributed significantly to this work are listed as authors. CB and RMV directed the trial from which the data are drawn. CB, MD, $E A$ and $\mathrm{CO}$ designed the analysis for this paper. MD implemented this design and undertook the analysis. DE provided additional statistical expertise. CB wrote the first draft of the paper which was then edited and commented on by MD, EA, LB, $\mathrm{JM}, \mathrm{CO}, \mathrm{JS}, \mathrm{DE}, \mathrm{EW}$ and RMV.

Funding This work was supported by the National Institute for Health Research (NIHR) in England under its Public Health Research Board (12/153/60) and the Education Endowment Foundation (no grant number). The views expressed in this publication are those of the authors and do not necessarily reflect those of the 
National Health Service, the NIHR or the Department of Health for England. The study funders (NIHR and Education Endowment Foundation) played no role in the study; collection, analysis and interpretation of data; the writing of the report or the decision to submit the manuscript for publication.

Competing interests None declared.

Patient and public involvement Patients and/or the public were involved in the design, or conduct, or reporting, or dissemination plans of this research. Refer to the Methods section for further details.

Patient consent for publication Not required.

Ethics approval The trial was prospectively registered as ISRCTN10751359 with the ISRCTN Registry on 30 January 2014 and approved by the UCL Ethics Committee (ref 5248/001).

Provenance and peer review Not commissioned; externally peer reviewed.

Data availability statement Data are available upon reasonable request. Data are available upon reasonable request.

Open access This is an open access article distributed in accordance with the Creative Commons Attribution 4.0 Unported (CC BY 4.0) license, which permits others to copy, redistribute, remix, transform and build upon this work for any purpose, provided the original work is properly cited, a link to the licence is given, and indication of whether changes were made. See: https://creativecommons.org/ licenses/by/4.0/.

\section{ORCID iDs}

Christopher Bonell http://orcid.org/0000-0002-6253-6498

Russell M Viner http://orcid.org/0000-0003-3047-2247

\section{REFERENCES}

1 Bonell C, Allen E, Warren E, et al. Initiating change in the school environment to reduce bullying and aggression: a cluster randomised controlled trial of the learning together (LT) intervention in English secondary schools. The Lancet 2018;392:2452-64.

2 Moore GF, Evans RE, Hawkins J, et al. From complex social interventions to interventions in complex social systems: future directions and unresolved questions for intervention development and evaluation. Evaluation 2019;25:23-45.

3 Rosas SR. Systems thinking and complexity: considerations for health promoting schools. Health Promot Int 2017;32:301-11.

4 Flay BR, Graumlich S, Segawa E, et al. Effects of 2 prevention programs on high-risk behaviors among African American youth: a randomized trial. Arch Pediatr Adolesc Med 2004;158:377-84.

5 Langford R, Bonell CP, Jones HE, et al. The who health promoting school framework for improving the health and well-being of students and staff. Cochrane Database Syst Rev 2014;2011:CD008958.

6 Patton GC, Bond L, Carlin JB, et al. Promoting social inclusion in schools: a group-randomized trial of effects on student health risk behavior and well-being. Am J Public Health 2006;96:1582-7.

7 Bonell C, Allen E, Christie D, et al. Initiating change locally in bullying and aggression through the school environment (inclusive): study protocol for a cluster randomised controlled trial. Trials 2014;15:381.
8 Morrison B. Restorative justice in schools. In: Elliot E, Gordon $\mathrm{RM}$, eds. New directions in restorative justice: issues, practices, evaluation. Cullompton, UK: Willan Publishing, 2005: 26-52.

9 Markham WA, Aveyard P. A new theory of health promoting schools based on human functioning, school organisation and pedagogic practice. Soc Sci Med 2003;56:1209-20.

10 Bond L, Wolfe S, Tollit M, et al. A comparison of the Gatehouse bullying scale and the peer relations questionnaire for students in secondary school. J Sch Health 2007;77:75-9.

11 Inchley J, Currie D, Young T, et al. Growing up unequal: gender and socioeconomic differences in young people's health and well-being. Copenhagen: WHO Europe, 2016. ISBN: 9789289051361.

12 Arseneault L. Annual research review: the persistent and pervasive impact of being bullied in childhood and adolescence: implications for policy and practice. J Child Psychol Psychiatry 2018;59:405-21.

13 Hair EC, Park MJ, Ling TJ, et al. Risky behaviors in late adolescence: co-occurrence, predictors, and consequences. J Adolesc Health 2009;45:253-61.

14 Copeland WE, Wolke D, Angold A, et al. Adult psychiatric outcomes of bullying and being bullied by peers in childhood and adolescence. JAMA Psychiatry 2013;70:419-26.

15 Lereya ST, Copeland WE, Costello EJ, et al. Adult mental health consequences of peer bullying and maltreatment in childhood: two cohorts in two countries. Lancet Psychiatry 2015;2:524-31.

16 Fisher HL, Moffitt TE, Houts RM, et al. Bullying victimisation and risk of self harm in early adolescence: longitudinal cohort study. BMJ 2012;344:e2683.

17 Winsper C, Lereya T, Zanarini M, et al. Involvement in bullying and suicide-related behavior at 11 years: a prospective birth cohort study. J Am Acad Child Adolesc Psychiatry 2012;51:271-82.

18 Fantaguzzi C, Allen E, Miners A, et al. Health-Related quality of life associated with bullying and aggression: a cross-sectional study in English secondary schools. Eur J Health Econ 2018;19:641-51.

19 Bevilacqua L, Shackleton N, Hale D, et al. The role of family and school-level factors in bullying and cyberbullying: a cross-sectional study. BMC Pediatr 2017;17:160.

20 Smith DJ. School experience and delinquency at ages 13 to 16 . Edinburgh: Centre for Law and Society, University of Edinburgh, 2006.

21 Bonell C, Humphrey N, Fletcher A, et al. Why schools should promote students' health and wellbeing. BMJ 2014;348:g3078.

22 Bonell C, Allen E, Opondo C, et al. Examining intervention mechanisms of action using mediation analysis within a randomised trial of a whole-school health intervention. J Epidemiol Community Health 2019;73:455-64.

23 Barrington-Trimis JL, Kong G, Leventhal AM, et al. E-Cigarette use and subsequent smoking frequency among adolescents. Pediatrics 2018;142:e20180486.

24 Smith PK, Mahdavi J, Carvalho M, et al. Cyberbullying: its nature and impact in secondary school pupils. J Child Psychol Psychiatry 2008;49:e385:376-85.

25 Bonell CP, Sorhaindo AM, Allen EE, et al. Pilot multimethod trial of a school-ethos intervention to reduce substance use: building hypotheses about upstream pathways to prevention. J Adolesc Health 2010;47:555-63.

26 Stephenson JM, Strange V, Forrest S, et al. Pupil-led sex education in England (ripple study): cluster-randomised intervention trial. Lancet 2004;364:338-46. 